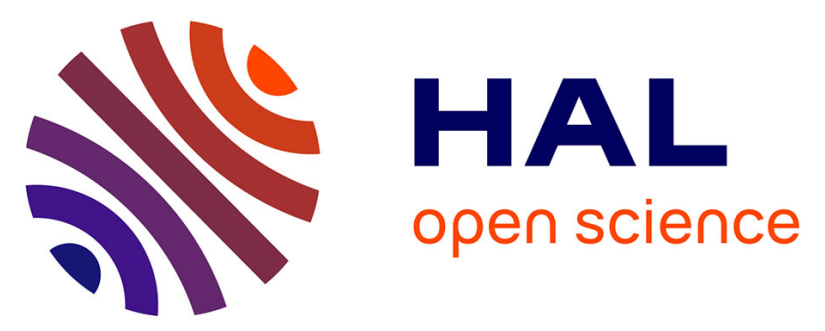

\title{
Characterization of Three Amino-Functionalized Surfaces and Evaluation of Antibody Immobilization for the Multiplex Detection of Tumor Markers Involved in Colorectal Cancer
}

\author{
Zhugen Yang, Yann Chevolot, Thomas Gehin, Vincent Dugas, Nicolas \\ Xanthopoulos, Vincent Laporte, Thierry Delair, Yasemin Ataman-Oenal, \\ Geneviève Choquet-Kastylevsky, Eliane Souteyrand, et al.
}

\section{- To cite this version:}

Zhugen Yang, Yann Chevolot, Thomas Gehin, Vincent Dugas, Nicolas Xanthopoulos, et al.. Characterization of Three Amino-Functionalized Surfaces and Evaluation of Antibody Immobilization for the Multiplex Detection of Tumor Markers Involved in Colorectal Cancer. Langmuir, 2013, 29 (5), pp.1498-1509. 10.1021/la3041055 . hal-00872600

\section{HAL Id: hal-00872600 https://hal.science/hal-00872600}

Submitted on 27 Apr 2019

HAL is a multi-disciplinary open access archive for the deposit and dissemination of scientific research documents, whether they are published or not. The documents may come from teaching and research institutions in France or abroad, or from public or private research centers.
L'archive ouverte pluridisciplinaire HAL, est destinée au dépôt et à la diffusion de documents scientifiques de niveau recherche, publiés ou non, émanant des établissements d'enseignement et de recherche français ou étrangers, des laboratoires publics ou privés.

$$
\text { Copyright }
$$




\title{
Characterization of three amino-functionalized
}

\section{surfaces and evaluation of antibody immobilization}

\author{
for the multiplex detection of tumor markers \\ involved in colorectal cancer
}

Zhugen Yang ${ }^{1}$, Yann Chevolot ${ }^{1}$, Thomas Géhin ${ }^{1}$, Vincent Dugas ${ }^{2}$, Nicolas Xanthopoulos ${ }^{3}$,

Vincent Laporte ${ }^{3}$, Thierry Delair ${ }^{4}$, Yasemin Ataman-Önal ${ }^{5}$, Geneviève Choquet-Kastylevsky ${ }^{5}$, Eliane Souteyrand ${ }^{1}$, Emmanuelle Laurenceau $^{1 *}$

${ }^{1}$ Université de Lyon, Institut des Nanotechnologies de Lyon (INL) - UMR CNRS 5270, Ecole Centrale de Lyon, 36 Avenue Guy de Collongue, 69134 Ecully cedex, France

${ }^{2}$ Université de Lyon, Institut des Sciences Analytiques (ISA) - UMR CNRS 52180, Université Claude Bernand-Lyon 1, 43 Boulevard du 11 novembre 1918, 69622 Villeurbanne cedex, France

${ }^{3}$ Ecole Polytechnique Fédérale de Lausanne - CIME (Interdisciplinary Center for Electron Microscopy), Station 12, CH - 1015 Lausanne, Switzerland

${ }^{4}$ Université de Lyon, Laboratoire d'Ingénierie des Matériaux Polymères-UMR CNRS, Université Claude Bernard-Lyon 1, 43 Boulevard du 11 novembre 1918, 69622 Villeurbanne cedex, France

${ }^{5}$ bioMérieux, Département bioMarqueurs, Marcy l'étoile 69280, France 


\section{ABSTRACT}

Antibody microarrays are powerful and high-throughput tools for screening and identifying tumor markers from small sample volumes of only a few microlitres. Optimization of surface chemistry and spotting conditions are crucial parameters to enhance antibodies immobilization efficiency and to maintain their biological activity. Here, we reported the implementation of antibody microarray for the detection of tumor markers involved in colorectal cancer. 3Dmicrostructured glass slide were functionalized with three different aminated molecules ((3aminopropyl) dimethylethoxysilane (APDMES), Jeffamine and chitosan) varying in their chain length, their amine density and their hydrophilic/hydrophobic balance. The physico-chemical properties of the resulting surfaces were characterized. Antibody immobilization efficiency through physical interaction was studied as a function of surface properties as well as a function of the immobilization conditions. The results show that surface energy, steric hindrance and $\mathrm{pH}$ of spotting buffer have great effects on protein immobilization. Under optimal conditions, biological activities of four immobilized anti-tumor marker antibodies were evaluated in multiplex immunoassay for the detection of the corresponding tumor markers. Results indicated that chitosan functionalized surface displayed the highest binding capacity and allowed to retain maximal biological activity of the four tested antibody/antigen systems. Thus, we successfully demonstrated the application of amino-based surface modification for antibody microarrays to efficiently detect tumor markers. 


\section{INTRODUCTION}

In the past decades, tumor markers have been routinely detected for cancer diagnosis in clinical oncology $^{1,2}$. However, due to the diversity and variation in different cancers, no single tumor marker is sensitive and specific enough to meet strict diagnostic criteria. Therefore, a combination of tumor markers is required to increase sensitivity and to establish distinct patterns to increase specificity ${ }^{3}$. Owing to multiplex detection, antibody microarrays appear as powerful tools for screening and identifying tumor markers, with the advantages of high-throughput, minimal sample volume requirement and low-cost. The immobilization procedure of antibodies is a crucial step in the elaboration of efficient antibody microarrays. Many studies have reported that analytical performance of microarray mainly depends on surface chemistry and detection conditions to prevent loss of biological activity as well as achieving high signal-to-noise ratio ${ }^{4-10}$.

Methods for immobilizing probe proteins on solid support range from covalent binding and affinity ligand capture, to simple physical adsorption ${ }^{11}$. Covalent binding gives a durable and stable linkage to the solid substrate, but can lead to partial loss of biological activity of the immobilized proteins ${ }^{12,13}$. Proteins can be covalently grafted onto chemically reactive surfaces, like epoxide or succinimide ester functionnalized surfaces, via their amino groups. Sometimes it is required to activate proteins for coupling and this may reduce the affinity of probe proteins. The pre-treatment of the probes burdens the preparation step and can limit the types of biomolecules that can be attached. Although the affinity capture retains the native conformation of immobilized proteins and should permit to control their orientation, it requires conjugation of the probe protein to be immobilized with an affinity tag (polyhistidine, biotin, etc) and surface modification of the substrate ${ }^{14}$. Compared to covalent binding and affinity, physical adsorption offers the simplest process for immobilization with ample binding capacity in some cases ${ }^{6,11}$. Amino-functionalizations of the surface are convenient and popular methods for protein 
immobilization via adsorption. Kusnezow and co-workers ${ }^{6}$ modified the glass slide with (3aminopropyl)trimethoxy silane (APTES) and poly-L-lysine to physically adsorb proteins onto surface, and evaluated the performances of such protein microarrays in comparison with other commercial glass slides. Signal intensity, background and spot morphology on poly-L-lysine modified surfaces were of sufficient quality. In contrast, APTES glass surfaces showed high background signal, which was about 4-5 times more intense than the background on poly-Llysine slides. Various reactive molecules (like functional polymers) with amine functionality have also been used to modify glass surface resulting in more selective and sensitive protein microarrays. Compared to the monolayers, multilayer coated surfaces with sufficient steric space better maintain the native conformation of proteins and prevent the loss of biological activities ${ }^{6,8}$, 15, 16. Kim et $\mathrm{al}^{15}$ modified the glass slide surfaces with either monolayers produced by silanisation or with polymer layers for protein chip implementation. Covalent immobilization yield and non-specific adsorption were examined by quantifying IgG-peroxidase conjugates immobilized to polymer-grafted glass substrates. Polymer-grafted glass substrates showed that non-specific adsorption was reduced by $10-60 \%$ as compared with 3-aminopropyltriethoxysilane (APTES)-treated substrate. In particular, chitosan-grafted substrates exhibited very low nonspecific protein adsorption. However, the proteins were covalently bound onto aminated surfaces through activation of glutaraldehyde, which made the process more complicated and probably reduced the affinity of probe proteins.

Our recent work ${ }^{10,17,18}$ demonstrated that immobilization of antibodies by physical adsorption onto chitosan functionalized surface could be better than covalent linking. Lower limit of detection and higher dynamic range were obtained depending on the tested antibody. In an effort to determine leading factors affecting performances of antibody microarray, different surface chemistries were investigated with respect to immobilization efficiency and biological activity of 
probe proteins. In this study, we evaluated the effect of three different chain-length aminofunctionalizations ((3-aminopropyl) dimethylethoxysilane (APDMES), Jeffamine, and chitosan) on the performances of antibody microarrays for the detection of tumor markers (CEA, HSP60, PDI and DEFA6) involved in colorectal cancer. APDMES, Jeffamine and chitosan are primary amine-bearing molecules. APDMES is small chain molecule with a monovalent silane that cannot polymerize. Thus it cannot form a multilayer on the surface. Jeffamine is a longer chain diamine. Its chain is composed of ethylene glycol and propylene glycol units increasing the distance between the amine group and the surface, as well as the chain mobility. Moreover, the presence of the propylene glycol units enhances the hydrophobic behaviour of the molecule. Finally, chitosan is a long chain highly aminated biopolymer composed of glucosamine units which give it a hydrophilic behaviour. These three aminated surfaces should vary in terms of surface energy, surface hindrance and amine surface density. The immobilization efficiency of

antibody and its biological activity were addressed as a function of these parameters. The spotting $\mathrm{pH}$ buffer was optimized for enhancing antibody immobilization while preserving biological recognition on the miniaturized system.

\section{MATERIALS AND METHODS}

\subsection{Materials.}

All chemicals were of reagent grade or the highest grade commercially available. They were used as received unless stated otherwise. Bovine serum albumin (BSA) lyophilized powder fraction IV, dimethyl sulfoxide (DMSO, anhydrous, $99.9 \%$ ), $0.01 \mathrm{M}$ phosphate-buffered saline (PBS, pH 7.4) at $25{ }^{\circ} \mathrm{C}(0.0027 \mathrm{M}$ potassium chloride and $0.138 \mathrm{M}$ sodium chloride), sodium dodecyl sulfate (SDS), sodium acetate, sodium bicarbonate, sodium carbonate, NHydroxysuccinimide (NHS), Jeffamine M-600 (polyoxypropylenediamine, $M_{\mathrm{w}}=600 \mathrm{~g} / \mathrm{mol}$ ), N, 
N'-diisopropylcarbodiimide (DIC), tetrahydrofuran (THF) (purum grade), polyvinylalcohol (PVA), (3-aminopropyl)dimethylethoxysilane (APDMES) and Coomassie brilliant blue (CBB) ( $>95 \%$ purified dye), all were obtained from Sigma-Aldrich (St. Quentin Fallavier, France). Tween 20 was purchased from Roth-Sochiel (Lauterbourg, France). Chitosan $\left(M_{\mathrm{w}}=470000\right.$ $\mathrm{g} / \mathrm{mol}$ ) was modified to obtain $94 \%$ of deacetylation degree (DD).

Borosilicate flat glass slide (76 x 26 x $1 \mathrm{~mm}$ ) were purchased from Schott (Mainz, Germany). Anti-tumor antibodies and tumor antigens were described in previous report ${ }^{19}$ for HSP60, in patent application WO2010/004214 for PDI and CEA $^{20}$ and in patent application WO2010/112777 for DEFA6 ${ }^{21}$. DL647 is a fluorescence dye (supplied by bioMérieux), used to conjugate with anti-CEA antibody for sandwich assay detection. Cy3-labeled goat anti-rabbit antibody immunoglobulin G (IgG) and Cy3-labeled streptavidin were purchased from Jackson ImmunoResearch and Sigma-Aldrich, respectively. Hydrogen peroxide $\left(\mathrm{H}_{2} \mathrm{O}_{2}\right)$ solution (30 vol.) was obtained from Gilbert Laboratories (Hérouville Saint-Claire, France). Ultrapure water (18.2 $\mathrm{M} \Omega$ ) was delivered by an Elga water system.

0.01 M PBS or PBS $1 \mathrm{X}(\mathrm{pH}$ 7.4) was prepared by dissolving the content of one pouch of dried powder in $1 \mathrm{~L}$ of ultrapure water. $0.02 \mathrm{M}$ sodium carbonate buffers at $\mathrm{pH} 10.7$ were prepared from $0.1 \mathrm{M} \mathrm{NaHCO}_{3}$ and $0.1 \mathrm{M} \mathrm{Na}_{2} \mathrm{CO}_{3}$ solutions in ultrapure water. Washing buffer contained PBS $1 \mathrm{X}$ and $0.1 \%$ Tween 20 (PBS-T) at pH 7.4. Blocking solution was prepared by dissolving $10 \mathrm{~g}$ of BSA in $100 \mathrm{ml}$ of PBS-T.

\subsection{Surface functionalization of microstructured glass slide.}

Flat microscope glass slides were microstructured as described previously ${ }^{22-24}$. In our microstructured glass slides, each well corresponds to independent microarray, which allows for multiplexed parameters detection (like buffer, tumor marker, surface chemistry etc) in one assay. Then they were aminosilanized with (3-aminopropyl) dimethylethoxysilane (APDMES) as the 
following protocol: The slides were washed with fresh piranha $\left(\mathrm{H}_{2} \mathrm{SO}_{4} / \mathrm{H}_{2} \mathrm{O}_{2}, 7: 3\right.$, v/v) for 30 min in the ultrasonic bath and rinsed with DI water. The substrates were dried under nitrogen stream at $150^{\circ} \mathrm{C}$ for $2 \mathrm{~h}$. APDMES in pentane (dried over molecular sieves) was added (APDMES from $0.06 \%$ to $0.6 \%, \mathrm{v} / \mathrm{v}$ ) and allowed to react at room temperature under stirring for $1 \mathrm{~h}$. Pentane was evaporated, and the reaction was allowed to proceed under nitrogen stream at $150^{\circ} \mathrm{C}$ overnight. Aminosilanized slides were rinsed with pentane, THF and dichloromethane in ultrasonic bath for 10 min each.

Alternatively, microstructured glass slides were silanized with tert-butyl-11-(dimethylamino) silylundecanoate (TDSUM) and carboxylic acids were deprotected as described previously ${ }^{9}$, 25-27. Activation of carboxylic acid was carried out with a mixture of NHS/DIC (molar ratio 1:1, $0.1 \mathrm{M}$ in THF) overnight at room temperature to obtain NHS surface. Then slides were washed for 10 min in THF and $10 \mathrm{~min}$ in dichloromethane under ultrasound.

NHS slides were substituted with Jeffamine (0.1 M, THF) overnight at room temperature to generate amino groups on the surface (Jeffamine surface). The slides were then washed for 30 min with $0.1 \%$ SDS at $70^{\circ} \mathrm{C}$ and rinsed with ultrapure water. Chitosan surface was obtained by derivatization of the NHS surface with chitosan solution at $1 \mathrm{mg} / \mathrm{mL}$ dissolved in acetic acid/DI$\mathrm{H}_{2} \mathrm{O}$ mixture. The concentration of acetic acid was determined by the degree of deacetylation (DD) of the chitosan and the expected concentration of chitosan. The structure formulas of the three amine reagents and surface modification steps are illustrated in Scheme 1. 

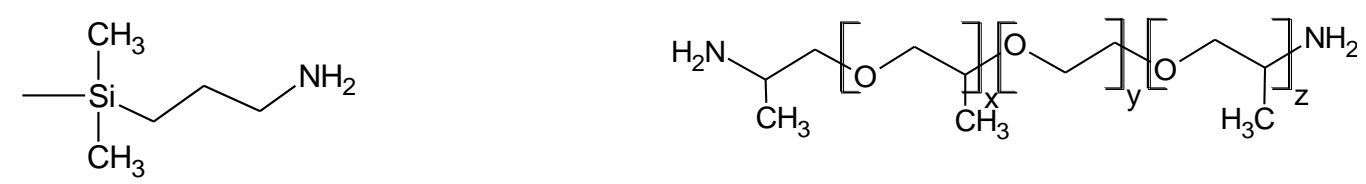

APDMES

Jeffamine

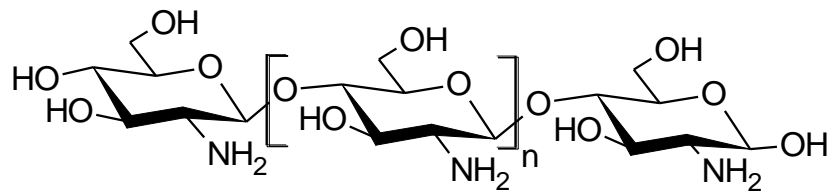

Chitosan 


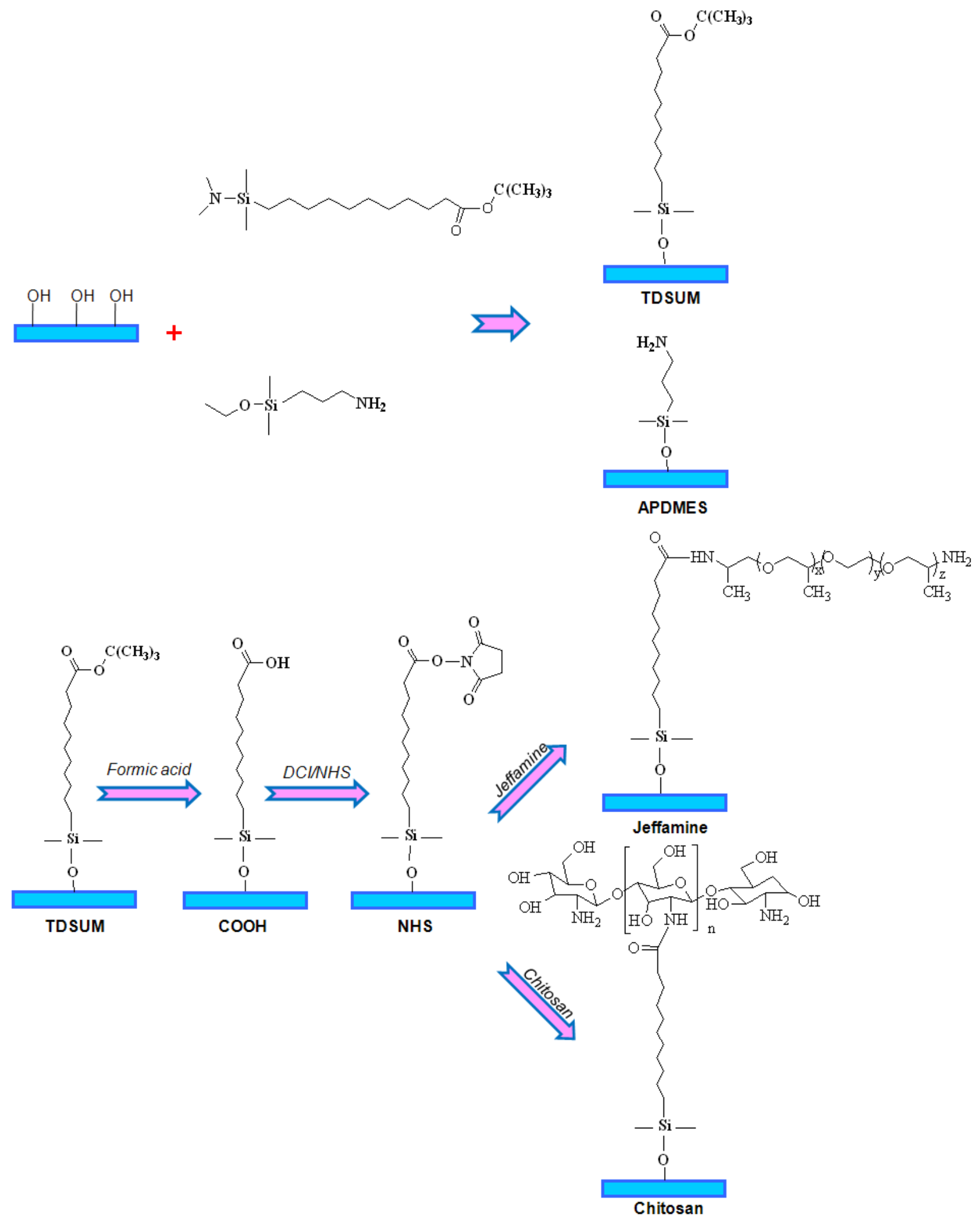

Scheme 1. Scheme of structure formula of APDMES, Jeffamine M-600 and chitosan; Successive surface modification steps with carboxysilane, aminosilane, jeffamine and chitosan derivatives. 


\subsection{Evaluation of amine grafting density on amino-functionalized surfaces.}

The grafting density of amino groups on the surface was determined using the modified ADECA ((amino density estimation by colorimetric Assay) method ${ }^{28}$ developed by Coussot et al. $^{29,30}$. ADECA method allows estimating from $0.03 \times 10^{14}$ to $40 \times 10^{14} \mathrm{~N}^{+} / \mathrm{cm}^{2}$.

Solution S1 was prepared by mixing $100 \mathrm{ml}$ methanol, $50 \mathrm{ml}$ glacial acetic acid and $850 \mathrm{ml} \mathrm{DI}$ water. CBB solution (S2) was prepared by dissolving $50 \mathrm{mg}$ of CBB in $50 \mathrm{~mL}$ methanol and 25 $\mathrm{mL}$ acetic acid under ultrasonic bath. Following complete dissolution, DI water was added to a final volume of $500 \mathrm{~mL}$. The final composition was $0.1 \mathrm{mg} / \mathrm{ml} \mathrm{CBB}$ in mixed solution of $10 \%$ (v/v) methanol, 5\% (v/v) acetic acid and $85 \%(\mathrm{v} / \mathrm{v}) \mathrm{H}_{2} \mathrm{O}$. The detection solution (S3) was prepared by mixing $50 \mathrm{~mL}$ of $1 \mathrm{M}$ ammonia buffer with $50 \mathrm{~mL}$ of methanol.

Amino surfaces were protonated in solution S1 for $10 \mathrm{~min}$, followed by immersion in solution $\mathrm{S} 2$ for $15 \mathrm{~min}$ for coloration of the surface, then washed with solution S1 for 3 x 10 min and DI water for $10 \mathrm{~min}$ under stirring. After drying by centrifugation, slides were transferred into solution S3 for 5 min under stirring for de-coloration, and this solution was collected for absorption measurement at $611 \mathrm{~nm}$. Added volume of solution S1, S2 and S3 was set in order to fully immerse glass slide sample. The amine density of the sample was quantified by the amount of $\mathrm{CBB}$ released in solution $\mathrm{S} 3$. Each surface was tested at least for four times, and negative control was freshly pirhanized glass slide.

\subsection{X-ray Photoelectron Spectroscopy (XPS).}

The XPS analysis was performed using an imaging Kratos Axis Ultra (UK) X-ray photoelectron spectrometer equipped with a conventional hemispherical analyzer. A monochromatized $\mathrm{Al} \mathrm{K \alpha}(1486.6 \mathrm{eV})$ operating at $150 \mathrm{~W}$ was employed. Spectrum acquisitions were performed under ultrahigh vacuum conditions (UHV, $10^{-9}$ Torr). Sample analysis area were $0.21 \mathrm{~mm}^{2}$ and take off was $90^{\circ}$ relative to the substrate surface. The pass energies were 80 and 20 
$\mathrm{eV}$ for wide-scan and high-resolution elemental scans, respectively. Charge compensation was performed with low-energy electrons $(0.1 \mathrm{eV})$. The C-C, C-H contribution was adjusted to 285 $\mathrm{eV}$. The data reduction (atomic concentration, shift, curve fitting,etc.) was performed with CasaXPS Version 2.3.14 software.

The operating software Vision 2, corrects for the transmission function. The relative sensitivity factors (RSF) were $0.278,0.477,0.780$ and 0.339 for C 1s, N 1s, O 1s and Si 2p respectively, used for determining the atomic concentrations (\% AC) of the surface composition. Background type was Shirley and Gaussian-Lorentzian peak shape (30\%) was used for peak fitting. Full widths at half-maximum (FWHM) for the component peaks of Si 2p, C 1s, N 1s and O 1s were constrained to be $1.5 \mathrm{eV}, 1.4 \mathrm{eV}, 1.7 \mathrm{eV}$ and $1.5 \mathrm{eV}$, respectively. Component peak positions of Si 2 p were based on the results by Alexander et al. ${ }^{31}$ who reported the binding energies of Si($\mathrm{O})_{1}, \mathrm{Si}(-\mathrm{O})_{2}, \mathrm{Si}(-\mathrm{O})_{3}$, and $\mathrm{Si}(-\mathrm{O})_{4}$ to be around $101.5,102.1,102.8$, and $103.4 \mathrm{eV}$, respectively.

\subsection{Contact angle measurement of amino-funtionalized surfaces}

Amino-functionalized glass slides were characterized for surface energy by contact angle measurements (Digidrop Goniometer, GBX, France). De-ionized water, Ethylene-glycol and Diiodomethane were used as the probe liquid in all measurements. To minimize the experimental error, the contact angle was measured at five random locations for each sample and the average value was reported. The surface energies were determined according to Owens-Wendt model.

\subsection{Protein microarray manufacturing and multiplex immunoassays}

Anti-CEA, anti-HSP60, anti-PDI and anti-DEFA6 capture antibodies were spotted (Biorobotics, Scienon) at the bottom of microwells of functionalized microstructured glass slides (1 type of antibody per microwell) at $10 \mu \mathrm{M}$. Spotting buffers were composed of $0.1 \mathrm{M}$ sodium acetate $(\mathrm{pH}=4.5)$, PBS $1 \mathrm{X}(\mathrm{pH}=7.4)$ or $0.05 \mathrm{M}$ sodium carbonate $(\mathrm{pH}=9.6)$ with $0.05 \%(\mathrm{v} / \mathrm{v})$ PVA as additive. Spotting buffers alone and goat anti-rabbit IgG-Cy3 at $0.6 \mu \mathrm{M}$ were spotted at the meantime for negative control and reference protein, respectively. Antibodies were allowed 
to react with functionalized surfaces under water-saturated atmosphere overnight at $4^{\circ} \mathrm{C}$. Slides were then washed for $2 \times 5$ min with PBS and for 5 min with PBS-T, and then dried by centrifugation for $3 \mathrm{~min}$ at $1300 \mathrm{rpm}$. The slides were blocked with 10\% BSA/PBS-T solution to limit further non specific adsorption ( $2 \mathrm{~h}$ at room temperature), washed for 3 x 5 min with PBS-T and then dried.

Microwells were then incubated with antigens (CEA, HSP60, PDI and DEFA6 diluted in 4\% BSA/PBS 1X) at different concentration (one antigen concentration per microwell, CEA and HSP60: $0.001 \mathrm{nM}, 0.01 \mathrm{nM} 0.1 \mathrm{nM}, 1 \mathrm{nM}, 10 \mathrm{nM}$ and $50 \mathrm{nM}$; PDI and DEFA6: $0.1 \mathrm{nM}, 1 \mathrm{nM}$, $10 \mathrm{nM}, 50 \mathrm{nM} 100 \mathrm{nM}$ and $500 \mathrm{nM}$ ). The slides were left to react for $1 \mathrm{~h}$ at room temperature in a water-saturated atmosphere, thoroughly rinsed for $3 \times 5$ min with PBS-T and then dried.

Microwells were then incubated with $0.5 \mu \mathrm{M}$ labeled detection antibodies (anti-CEA-DL647, biotinylated anti-HSP60, biotinylated anti-PDI, biotinylated anti-DEFA6 diluted in 4\% BSA/PBS-T), for $1 \mathrm{~h}$ at room temperature in a water-saturated atmosphere. After washing and drying, microwells were then incubated with $1 \mu \mathrm{M}$ streptavidin-Cy3 for $1 \mathrm{~h}$ at room temperature in a water-saturated atmosphere, except for the wells incubated with anti-ACE-DL647. The slides were washed for 3 x 5 min with PBS-T and for 1 min with DI water, followed by drying.

\subsection{Fluorescence scanning}

Slides were scanned with the Microarray scanner, GenePix 4100A software package (Axon Instruments) at wavelengths of $532 \mathrm{~nm}$ with photomultiplier tube (PMT) 500. The fluorescence signal of each antibody was determined as the average of the median fluorescence signal of six spots, and the value was divided by the signal of background from surface to get the signal-tonoise ratio (SNR). 


\section{RESULTS AND DISCUSSION}

\subsection{Amine density of functionalized glass slides.}

Organosilanes are widely used in the fields of biosensors and biochip technology. In previous studies we reported use of silanizations for effectively introducing carboxylic group on the surface of silicon/glass slides for biochip manufacturing ${ }^{26}, 32$. The grafting reaction of a monofunctional silane (APDMES and TDSUM) was selected because it is simpler and more reproducible than those of multifunctional silanes. Indeed, compared to the grafting of multifunctional silanes (e.g. APTES), monofuncitonal silanes are less sensitive to experimental conditions like moisture for example. The grafting process (by impregnation) used in our experimental set-up allows to overcome the lower reactivity of such monofunctional silanes. As a follow-up of this work, microstructured glass slides were functionalized with APDMES at various concentrations and quantitative analysis of amine density was performed as described in references $^{29}, 30,33$. Indeed, Coussot et al. have developed a rapid method based on the adsorption/desorption of Coomassie Brillant Blue (CBB) for the estimation of available $\mathrm{N}^{+}$ groups on surfaces of polymeric and silica-based materials.

As shown in Figure 1A, the amine density on aminosilanized glass slides reached a maximum around $1.3 \times 10^{14}$ amino groups $/ \mathrm{cm}^{2}$ and did not depend on the concentration of APDMES introduced in the reaction mixture, in the range tested. Our results are in agreement with Oh et al. ${ }^{34}$ who have prepared aminosilane layers on glass slides with APDMES and determined the amine density as being $10^{14}$ amino groups $/ \mathrm{cm}^{2}$. In another study ${ }^{35}$, covalently bound monolayers of aminosilane were deposited on dehydrated silicon surface by chemical vapor deposition. The results showed that aminosilane concentrations over a wide range did not affect surface coverage because the number of reactive sites on the surface was limited. Dugas et al. have demonstrated the complete reaction of all surface accessible substrate silanols with monofunctional silane ${ }^{36}$. 
Similarly, in the present study, the limiting factor is most probably the number of reactive silanols on the substrate surface. Complete reaction is achieved with $0.05 \%$ of APDMES.

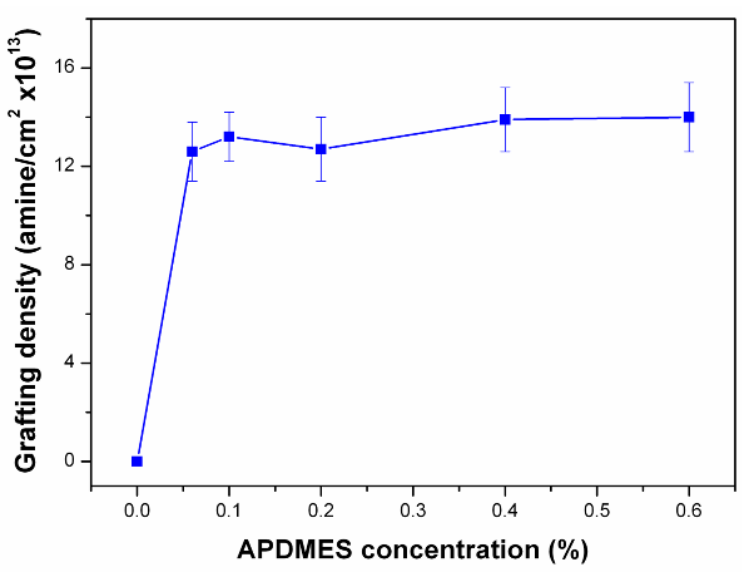

A

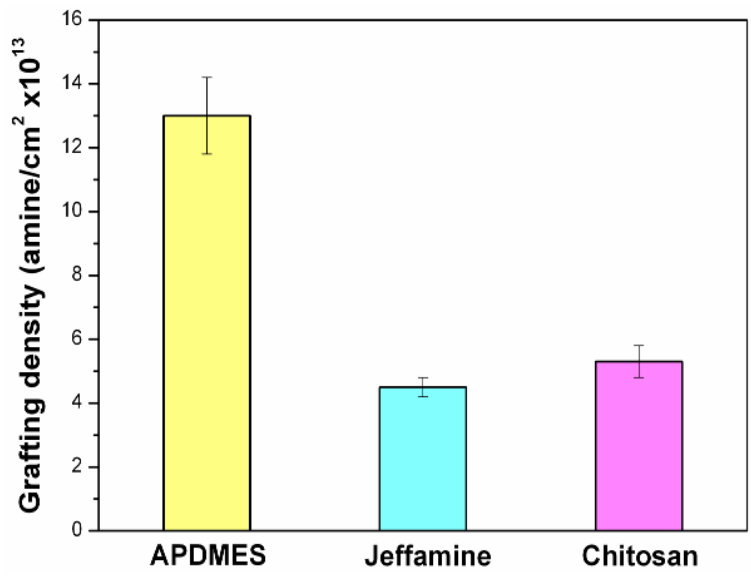

B

Figure 1. Effect of APDMES concentration ( $\mathrm{v} / \mathrm{v}$ in pentane) on grafting density on glass slide (A), and (B) comparison of functionalized glass slides with APDMES (0.1\% v/v), Jeffamine $(0.1 \mathrm{M})$ and chitosan $(1 \mathrm{mg} / \mathrm{mL})$.

Jeffamine and chitosan were grafted by reaction with NHS activated carboxylic groups from TDSUM modified surfaces (Scheme 1). The reaction leads to the formation of an amide bond. Jeffamine is a diamine that can either react with only one NHS ester group leading to an aminated surface or react with two adjacent NHS ester groups leading to "bridge" formation with no available amine. Chitosan is a polyaminated polymer, whose amine density was also determined with the ADECA method (Figure 1B). Results indicated that functionalization with these two polymers led to about three time less amine density than with APDMES (Jeffamine: $4.5 \times 10^{13}$ amino groups $/ \mathrm{cm}^{2}$, chitosan: $5.3 \times 10^{13}$ amino groups $/ \mathrm{cm}^{2}$ ).

The chitosan used in this study was of high molecular weight $(\mathrm{Mw}=470000 \mathrm{~g} / \mathrm{mol})$ with a high degree of deacetylation (94\%). These characteristics correspond to a long-chain structure 
bearing a large amount of amino groups. The lower amine density observed on chitosan surface suggests that, steric hindrance or electrostatic repulsion between chitosan molecules may occur leading to low amount of available amino groups on the surface. It is also possible that CBB could not reach all surface amino groups due to steric hindrance or diffusion limitations related to the long polymeric chains. However, the amine density of chitosan modified surfaces was similar to the one observed on Jeffamine surfaces.

\subsection{XPS analysis of modified surfaces.}

Tables 1a and $1 \mathrm{~b}$ summarize the XPS atomic percentage and contributions of C 1s, N 1s, Si 2p and $\mathrm{O} 1 \mathrm{~s}$ lines.

Table 1a. Atomic concentration calculated from XPS analysis, N/Si (-O) $)_{1}$ : ratio between nitrogen and silicon atomic concentrations.

\begin{tabular}{|c|c|c|c|c|c|c|}
\hline \multirow{2}{*}{ Surfaces } & \multicolumn{4}{|c|}{ Atomic concentration (AC\%) } & \multirow{2}{*}{$\mathrm{Si}(-\mathrm{O})_{1}(\%)$} & \multirow{2}{*}{$\mathrm{N} / \mathrm{Si}(-\mathrm{O})_{1}$} \\
\hline & $\mathrm{C}$ & $\mathrm{Si}$ & $\mathrm{N}$ & $\mathrm{O}$ & & \\
\hline APDMES & 14.6 & 27.7 & 1.24 & 56.4 & 4.9 & 1.0 \\
\hline TDSUM & 10.6 & 29.0 & - & 60.4 & 1.1 & - \\
\hline Jeffamine & 22.1 & 25.0 & 0.56 & 52.4 & 1.4 & - \\
\hline Chitosan & 14.0 & 27.6 & 0.42 & 58.0 & 2.8 & - \\
\hline
\end{tabular}

Table 1b. XPS contributions of the $\mathrm{C} 1 \mathrm{~s}, \mathrm{~N} \mathrm{1s}$, Si $2 \mathrm{p}$ and $\mathrm{O}$ 1s lines for APDMES, Jeffamine and chitosan surfaces.

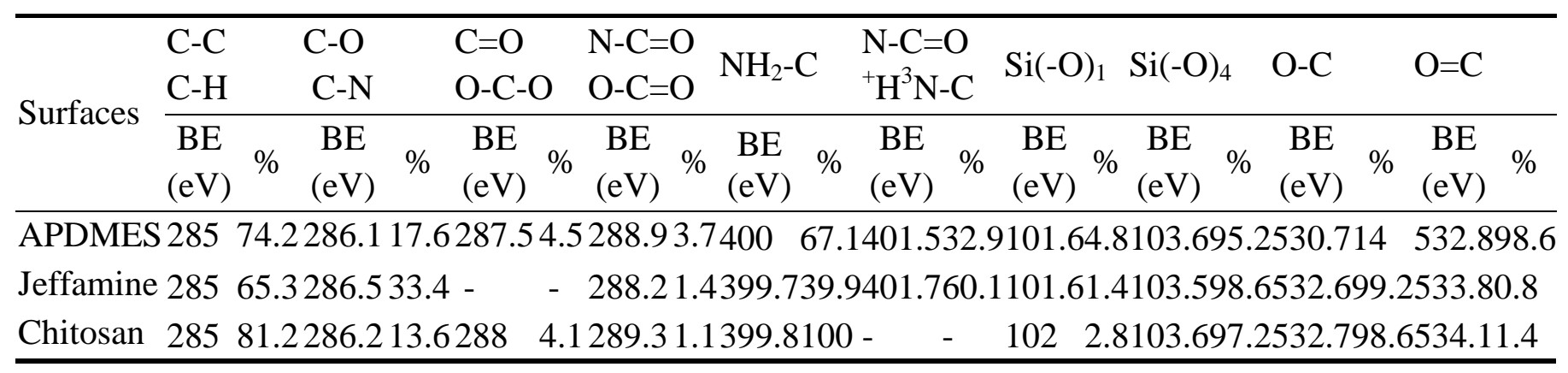


Figure 2 shows the high-resolution XPS spectra of Si $2 p$ and N 1s of piranha cleaned silica surface and mono-functional silane APMDES modified silica. The presence of nitrogen (Table 1) on APMDES surface confirmed that APDMES was successfully introduced with our protocol. Besides, two fit peaks were present on the high-resolution N 1s spectra (Figure 2 B2) revealing two contributions, which were associated with a free amine $\mathrm{NH}_{2}-\mathrm{C}$ (around $400 \mathrm{eV}$ ) and protonated amine $\mathrm{NH}_{3}^{+}-\mathrm{C}$ (around $\left.401.6 \mathrm{eV}\right)^{37}$, respectively. The protonated amine component peak is attributed to interactions between the APDMES amine groups and surface silanols on the silica substrate, resulting in proton transfer to the amine group ${ }^{38}$. The presence of the monofunctional silane on APDMES surface is further supported by the peak at $101.6 \mathrm{eV}$ on the $\mathrm{Si} 2 \mathrm{p}$ peak corresponding to $\mathrm{Si}(\mathrm{O}-)_{1}$. Indeed, Alexander and co-workers ${ }^{31}$ have shown that the $\mathrm{Si} 2 \mathrm{p}$ component peaks in $\mathrm{Si}(-\mathrm{O})_{\mathrm{x}}$ films can be resolved and quantitative peak fitting can be performed based on two assumptions: (1) each Si atom has a valence of four, resulting in four component peaks within the Si 2p envelope and (2) the shift of the Si binding energies depends primarily on the number of oxygen atoms attached to the Si. The four component peaks of the Si $2 p$ envelope are referred to as $\mathrm{Si}(-\mathrm{O})_{1}, \mathrm{Si}(-\mathrm{O})_{2}, \mathrm{Si}(-\mathrm{O})_{3}$, and $\mathrm{Si}(-\mathrm{O})_{4}$, where the oxygen subscript indicates how many oxygen atoms are attached to the $\mathrm{Si}$ atom. This deconvolution is widely used to characterize $\mathrm{Si}(-\mathrm{O}) \mathrm{x}$ containing films on solid surfaces. ${ }^{39,40}$ The covalent attachment of a monofunctional silane to $\mathrm{SiO}_{2}$ results in the formation of a single siloxane bridge between the monovalent silane and the silanol groups of the surface. The silicon atom of the silane is then involved in only one bond with an oxygen atom and three bonds with carbon atoms. This silicon atom can be distinguished from the silicon atoms of the underlying silica involved in four bonds with oxygen atoms. As shown in Figure 2 A for the piranha cleaned surface, only one component corresponding to $\mathrm{Si}(-\mathrm{O})_{4}$ is observed. In Figure $2 \mathrm{~B}$, curve fitting of APDMES grafted silica 
demonstrated the presence of the same contribution at $103.6 \mathrm{eV}$ and an additional contribution at $101.6 \mathrm{eV}$. According to Alexander et al..$^{31}$, this new contribution was assigned to the $\mathrm{Si}(-\mathrm{O})_{1}$ component peak, which is indicative of the $\mathrm{Si}(-\mathrm{O})_{1}$ of APDMES bonded to the silica surface. This is further supported by the fact that the ratio of the $\mathrm{Si}(-\mathrm{O})_{1}$ over the area of the $\mathrm{N} 1 \mathrm{~s}$ after correction by the RSF is close to 1 as expected from the molecule structure (one $\mathrm{Si}(-\mathrm{O})_{1}$ for one N).

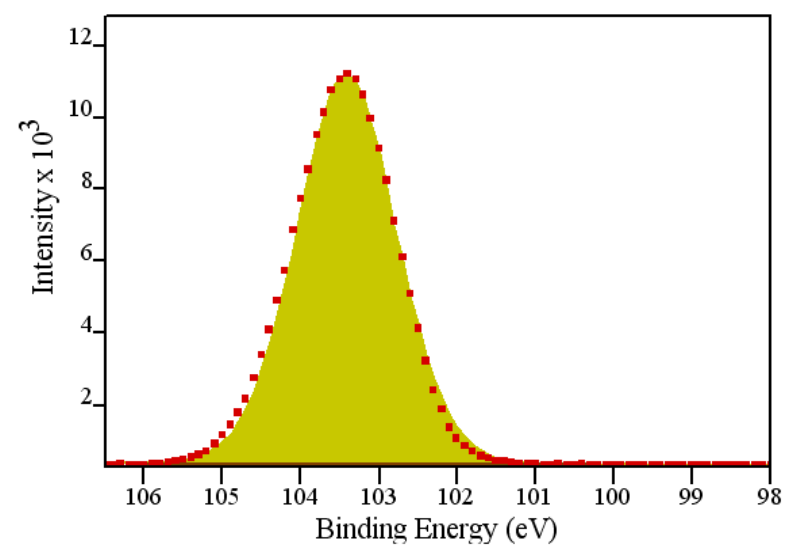

A

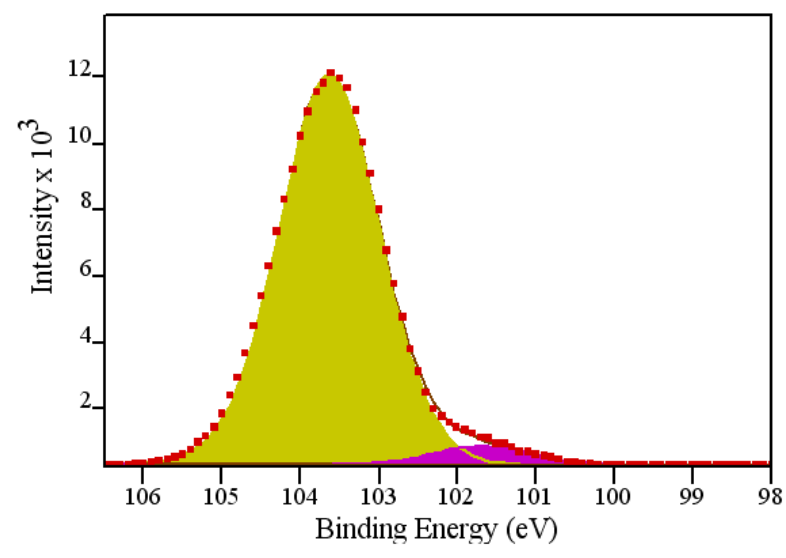

B1

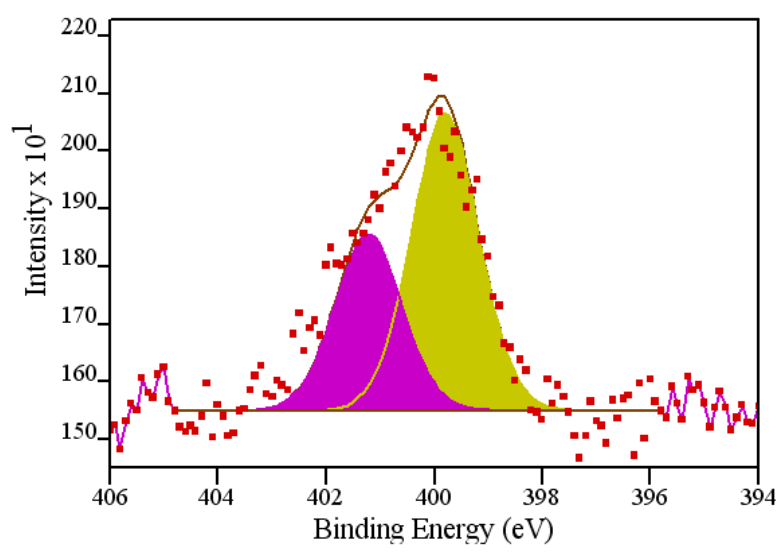

B2

Figure 2. High-resolution XPS spectra of piranha cleaned silica surface $\mathrm{Si} 2 \mathrm{p}$ (A) and of APDMES functionalized silica surface Si 2p (B1) and N 1s (B2). 
Table 1 gives the respective atomic concentration ( $\mathrm{AC} \%$ ) of $\mathrm{C}, \mathrm{Si}, \mathrm{N}, \mathrm{O}$ as well as the relative contribution of $\mathrm{Si}(-\mathrm{O})_{1}$ in the $\mathrm{Si} 2 \mathrm{p}$ for APDMES, TDSUM, Jeffamine and chitosan modified surfaces. The relative contribution $(\%)$ of $\mathrm{Si}(-\mathrm{O})_{1}$ was calculated as the contribution of the $\mathrm{Si}(-$ $\mathrm{O})_{1}$ determined by curve fitting over the total area of the $\mathrm{Si} 2 \mathrm{p}\left(\mathrm{Si}(-\mathrm{O})_{1}\right.$ and $\left.\mathrm{Si}(-\mathrm{O})_{4}\right)$. As mentioned above, $\mathrm{Si}(-\mathrm{O})_{1}$ signal originated only from the silane molecule while the $\mathrm{Si}(-\mathrm{O})_{4}$ originated from the underlying silica. Therefore, this ratio is independent on subsequent surface layers as far as they do not contain silicon. On the contrary, due to the mean inelastic free path of electrons (constant probing depth), increased surface coverage results in decreased signal originating from the substrate and therefore the decrease of $\mathrm{Si} 2 \mathrm{p}$ atomic percentage. The percentages of $\mathrm{Si}(-\mathrm{O})_{1}$ for APDMES and TDSUM modified silica were $4.9 \%$ and $1.7 \%$ respectively. The $\mathrm{Si}(-\mathrm{O})_{1}$ for TDSUM was the mean of $1.1 \%, 1.4 \%$ and $2.8 \%$ corresponding to TDSUM, Jeffamine and chitosan surfaces. A lower Si atomic percentage was observed on APDMES surface $(27.7 \%)$ compared to TDSUM surface $(29.0 \%)$. These results suggest that a slightly higher surface coverage was obtained with APDMES compared to TDSUM but remained in the same order of magnitude for both surfaces.

Upon reaction of TSDUM surface with either Jeffamine or chitosan, the N 1s AC\% increased from 0 to 0.56 and $0.42 \%$ respectively, whereas the $\mathrm{Si} 2 \mathrm{p}$ AC\% decreased as expected. According to the $\mathrm{N}$ 1s AC\%, the amine surface densities are lower for these two surfaces confirming the results obtained from the amine colorimetric titration.

Figure 3 presents the spectra of $\mathrm{N} 1 \mathrm{~s}$ and $\mathrm{C} 1 \mathrm{~s}$ of Jeffamine and chitosan surfaces obtained after reaction with TDSUM modified surfaces (XPS spectra not shown) ${ }^{26,41}$ leading to the formation of amide bonds. Unreacted amine groups are also present as demonstrated by CBB 
titration. The four peaks corresponded to C-C, C-H at $285 \mathrm{eV}, \mathrm{C}-\mathrm{O}, \mathrm{C}-\mathrm{N}$ at $286.1 \mathrm{eV}, \mathrm{C}=\mathrm{O}, \mathrm{O}-\mathrm{C}-$ $\mathrm{O}$ at $287.5 \mathrm{eV}$ and very weakly $\mathrm{N}-\mathrm{C}=\mathrm{O}, \mathrm{O}-\mathrm{C}=\mathrm{O}$ at around $289 \mathrm{eV}$ were observed on both surfaces. ${ }^{42,43}$ The contribution at $286.1 \mathrm{eV}$ can be attributed to the polyoxypropylene backbone of Jeffamine or to the polysaccharide backbone of chitosan. On N 1s spectra of Jeffamine, two peaks are observed at $399.7 \mathrm{eV}$ and $401.7 \mathrm{eV}$; These contributions can be assigned to $\mathrm{NH}_{2}-\mathrm{C}$ or $\mathrm{N}-\mathrm{C}=\mathrm{O}$ respectively. Alternatively, they can be attributed to $\mathrm{N}-\mathrm{C}=\mathrm{O}$ and ${ }^{+} \mathrm{H}_{3} \mathrm{~N}-\mathrm{C}$ or $\mathrm{NH}_{2}-\mathrm{C}$ and ${ }^{+} \mathrm{H}_{3} \mathrm{~N}-\mathrm{C}$ (Figure 3 A2). The reaction proceeds in tetrahydrofuran, an aprotic solvent. So most probably the contribution at $399.7 \mathrm{eV}$ corresponds to $\mathrm{NH}_{2}-\mathrm{C}$ and the contribution at $401.7 \mathrm{eV}$ to a nitrogen involved in an amide bond. In the case of chitosan, the contribution at 401.7 is not observed and would suggest that reaction between the NHS ester and the amine of the chitosan did not occur. This suggests that chitosan is mostly physisorbed on the TDSUM surface despite the washing step with $18.2 \mathrm{M} \Omega$ water. 


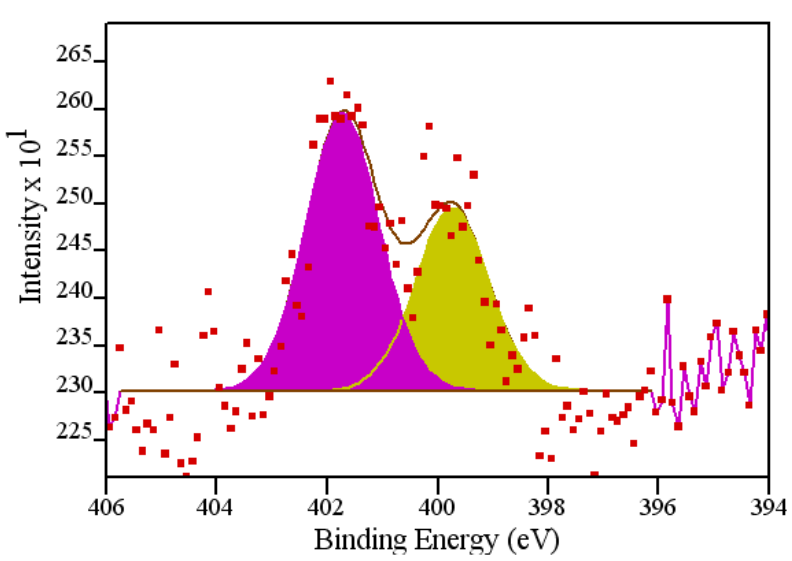

A1

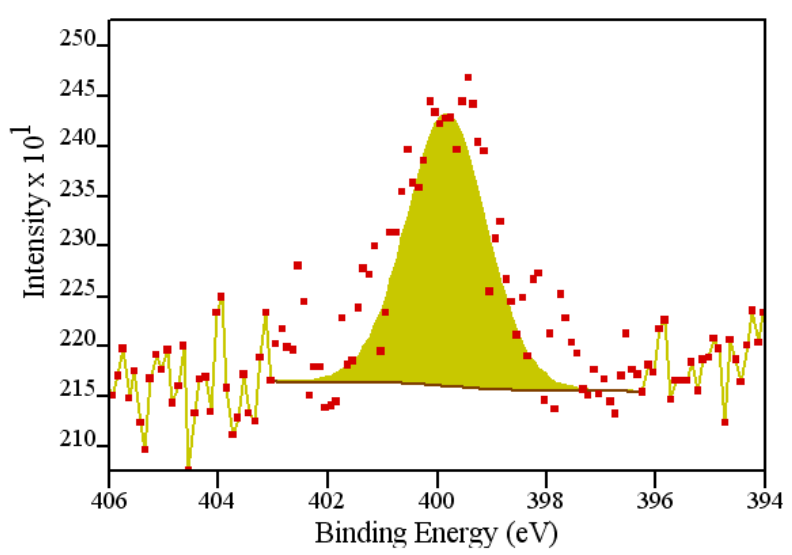

B1

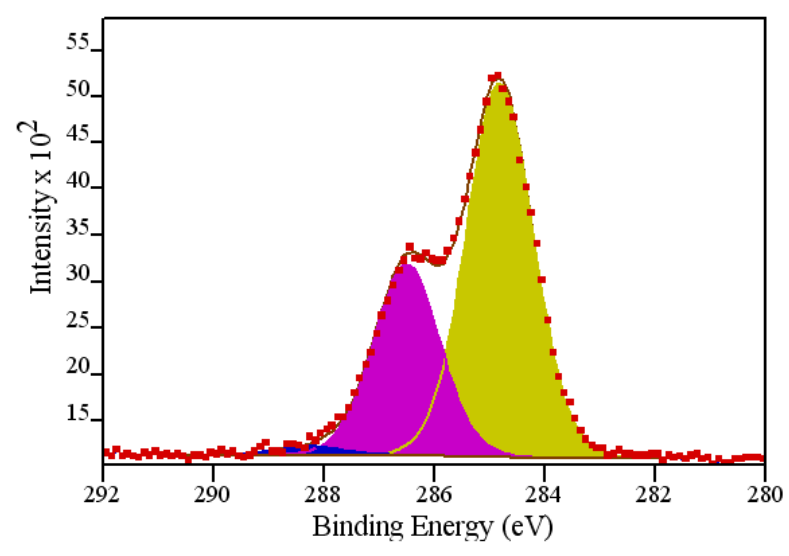

A2

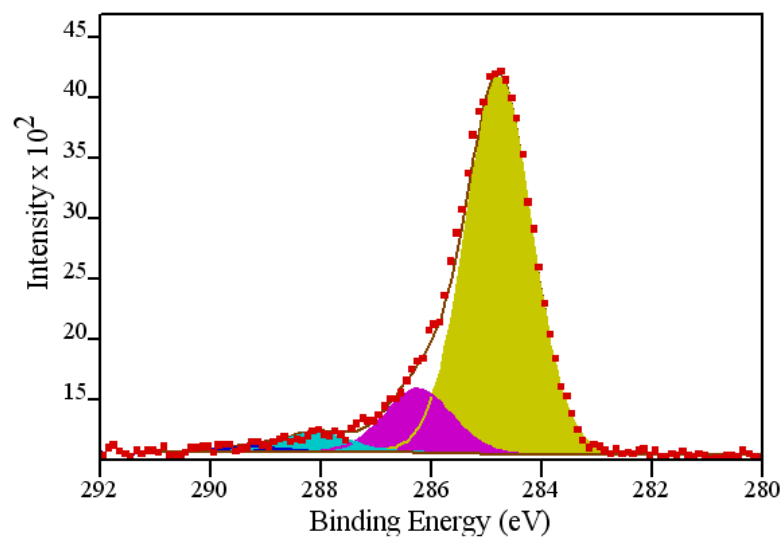

B2

Figure 3. High-resolution XPS spectra for Jeffamine (A) and chitosan (B) surfaces. A1, B1 are relative to $\mathrm{N}$ 1s spectra. $\mathrm{A} 2$ and $\mathrm{B} 2$ are relative to $\mathrm{C} 1 \mathrm{~s}$ spectra.

\subsection{Surface energy of amino-functionalized glass slides.}

The three amine surfaces were characterized by contact angle measurements to evaluate surface energy. The surface energies, viz., the total energy $\left(E_{\mathrm{T}}\right)$, the dispersive energy $\left(E_{\mathrm{D}}\right)$ and the polar energy $\left(E_{\mathrm{P}}\right)$ were calculated from the wetting angle $(\theta)$ accordingly to the Owens-Wendt equations. As is shown in Table 2, the total surface energy was higher for polymer functionalized 
surface than for aminosilane and Jeffamine functionalized surfaces. Although APDMES and Jeffamine displayed comparable polar energy $6.2 \mathrm{~mJ} / \mathrm{m}^{2}$ and $7.1 \mathrm{~mJ} / \mathrm{m}^{2}$, respectively, Jeffamine surface was more hydrophilic than APDMES surface as indicated its higher total surface energy. This could be attributed to the polyoxyproplene backbone of Jeffamine compared to the alkyl chain of ADPMES. While Jeffamine and chitosan present comparable dispersive component of the surface energy, chitosan surface was the most hydrophilic surface due to its high polar energy which was about two times that of APDMES and Jeffamine surfaces. Indeed, chitosan is a natural polysaccharide with hydrophilic characteristic as already described ${ }^{44,45}$, and results obtained for APDMES surface is also in agreement with published data ${ }^{35,46}$.

Table 2. Wetting properties of amino-functionalized surfaces determined with Owens-Wendt model; $E_{\mathrm{T}}, E_{\mathrm{P}}$ and $E_{\mathrm{D}}$ are relative to the total, polar and dispersive energy, respectively.

\begin{tabular}{lcccccc}
\hline \multirow{2}{*}{ Surfaces } & \multirow{2}{*}{$\begin{array}{c}E_{\mathrm{T}} \\
\left(\mathrm{mJ} / \mathrm{m}^{2}\right)\end{array}$} & \multirow{2}{*}{$\begin{array}{c}E_{\mathrm{P}} \\
\left(\mathrm{mJ} / \mathrm{m}^{2}\right)\end{array}$} & $\begin{array}{c}E_{\mathrm{D}} \\
\left(\mathrm{mJ} / \mathrm{m}^{2}\right)\end{array}$ & water & $\begin{array}{c}\text { Ethylene- } \\
\text { Glycol }\end{array}$ & $\begin{array}{c}\text { Diiodo- } \\
\text { methane }\end{array}$ \\
\hline APDMES & $31.6 \pm 2.1$ & $6.2 \pm 0.7$ & $25.4 \pm 1.9$ & $79.5 \pm 0.2$ & $64.6 \pm 0.4$ & $59.6 \pm 0.5$ \\
Jeffamine & $38.4 \pm 3.2$ & $7.1 \pm 0.5$ & $31.3 \pm 2.8$ & $74.1 \pm 0.2$ & $50.5 \pm 0.5$ & $51 \pm 0.4$ \\
Chitosan & $43.7 \pm 3.5$ & $12.4 \pm 1.0$ & $31.4 \pm 2.4$ & $62.4 \pm 0.5$ & $44.5 \pm 0.7$ & $47.2 \pm 0.7$ \\
\hline
\end{tabular}

\subsection{Characterization of antibody immobilization on amino-functionalized surfaces.}

Antibody immobilization was characterized by fluorescence scanning using a goat anti-rabbit IgG labelled with cyanine $3(\mathrm{Cy} 3)$. The labelled antibody was spotted at $0.6 \mu \mathrm{M}$ in various $\mathrm{pH}$ buffers in order to evaluate the antibody immobilization capacity of the amino-functionalized surfaces. The results are expressed as signal to noise ratio (SNR) (Figure 4). For the three surfaces, the SNR increased with increasing $\mathrm{pH}$ values of buffer suggesting charge dependence for the antibody immobilization. The electrostatic interactions between positively charged amino 
groups on the surface and antibodies bearing negative charge, increased with increasing $\mathrm{pH}$ value of buffer (in the range of $\mathrm{pH}$ studied) except for chitosan functionalized surface. Moreover, considering one buffer, the immobilization yield of antibodies is 2 to 6 times higher on chitosan surface than on the other two amino-functionalized surfaces. Whereas Jeffamine surface displayed half lower amine density than APDMES (Figure 1B), its immobilization density for antibodies was slightly higher. Wetting properties of both surfaces suggested that Jeffamine surface developed more Van der Waals and non-site-specific interactions, relative to the dispersive energy of the surface, with antibodies than APDMES surface. Chitosan surface displayed the same amine density as Jeffamine surface, but three main physico-chemical differences could explain the higher antibody immobilization density of chitosan surfaces. First, the chitosan sample used has a high molecular weight, $\mathrm{Mw}=470000 \mathrm{~g} / \mathrm{mol}$, hence developing high immobilization surface area. Second, chitosan surface was shown to be more hydrophilic than the other two surfaces, with higher polar energy part. Third at $\mathrm{pH} 7.4$ and above, chitosan is poorly charged and most probably the interactions developed with antibodies are hydrogen bonding. These low energy interactions do not block the protein at the outer surface of the polymer layer but allows, by successive H-bond breaking and forming steps, a penetration of the immunoglobulin within the polysaccharide layer. However, the immobilization capacity of a surface was not directly correlated to its ability to preserve the biological activity of the immobilized proteins. 


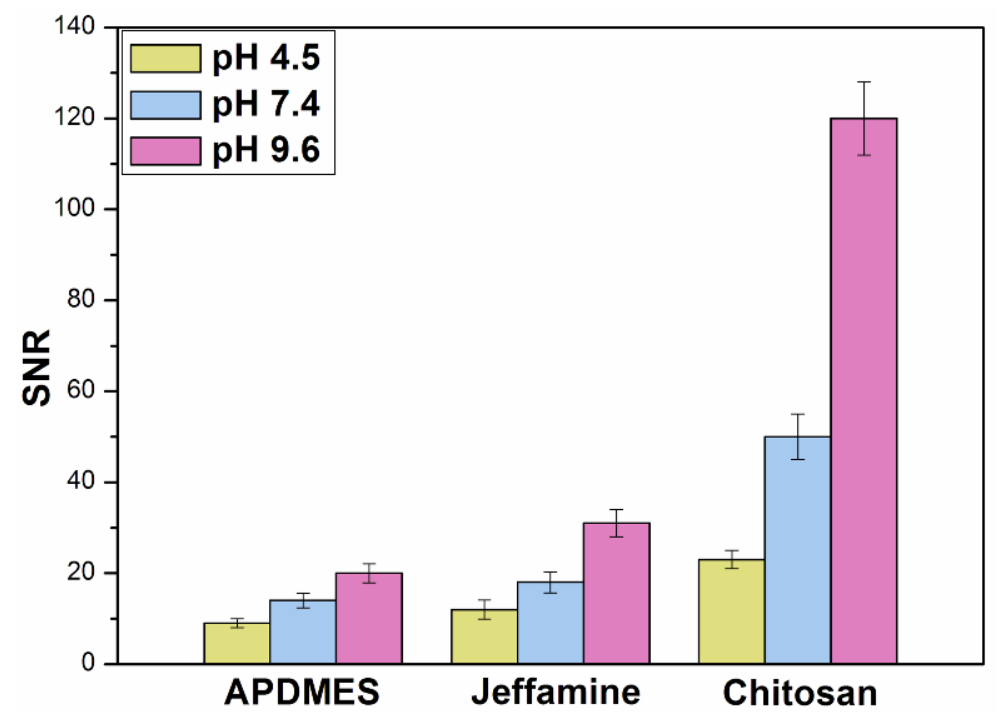

Figure 4. Signal to noise ratio from immobilization of IgG-Cy3 in different spotting buffer (sodium acetate, $\mathrm{pH}=4.5$; $\mathrm{PBS}, \mathrm{pH}=7.4$; sodium carbonate, $\mathrm{pH}=9.6$ ) on APDMES, Jeffamine and chitosan surfaces.

\subsection{Detection of tumor markers on antibody microarray.}

According to previous results ${ }^{10}$, four monoclonal antibodies directed against tumor markers involved in colorectal cancer (anti-CEA, anti-HSP60, anti-PDI and anit-DEFA6) were spotted at $10 \mu \mathrm{M}$ on the amino-functionalized surfaces in the different $\mathrm{pH}$ buffers (sodium acetate $\mathrm{pH} 4.5$, PBS pH 7.4 and sodium carbonate $\mathrm{pH}$ 9.6). These capture antibodies were allowed to interact with corresponding tumor markers at various concentrations. Detection of the biological recognition was performed using biotinylated monoclonal antibodies directed against another epitope of the corresponding tumor marker, followed by incubation with Cy3-labeled streptavidin. Figure 5 presents the effects of the buffer $\mathrm{pH}$ on the biological activity of anti-CEA antibody immobilized on chitosan surface for the detection of CEA. The four anti-tumor marker antibody/tumor marker systems displayed the same behavior on each amino-functionalized surface (data not shown). Typically, SNR increased with the increasing tumor marker 
concentration and $\mathrm{pH}$ value of spotting buffer. The best immunoassay response was obtained with carbonate buffer ( $\mathrm{pH}$ 9.6) in agreement with data obtained for IgG-Cy3 immobilized on the various amino-functionalized surfaces. This result demonstrated that carbonate buffer ( $\mathrm{pH} 9.6)$ as the spotting buffer not only facilitated the immobilization of antibodies on aminated surfaces but also allowed to maintain their biological activity. Therefore, sodium carbonate buffer at pH 9.6 was chosen as spotting buffer in the following experiments.

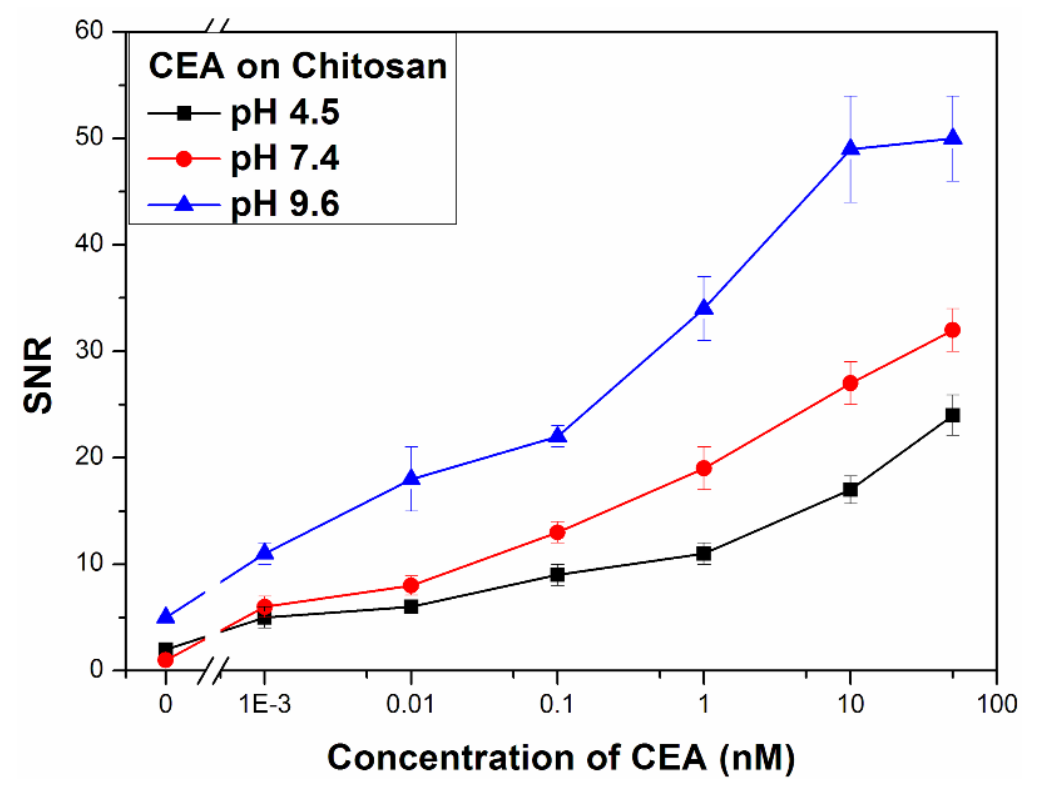

Figure 5. Signal to noise ratio (SNR) relative to biological recognition of anti-CEA antibody spotted in different $\mathrm{pH}$ buffers on chitosan surface, versus CEA concentrations.

Figure 6 illustrates the results of multiplex immunoassays for the detection of the four tumor markers tested on the various aminated surfaces developed for antibody microarray implementation. Our recent report ${ }^{10}$ showed that CEA and HSP60 had more sensitive responses than PDI and DEFA6 on various surfaces including chitosan surface. Therefore the concentration scale for CEA and HSP60 was set from $0.001 \mathrm{nM}$ to $50 \mathrm{nM}$ and for PDI and DEFA6 was set 
from $0.1 \mathrm{nM}$ to $500 \mathrm{nM}$. Comparison of the graphs demonstrated that, on the three aminofunctionalized surfaces, SNR increased with increasing the tumor marker concentration. But the range of SNR values depended both on the tumor marker and on the kind of aminated surface. SNR was related to the biological recognition between the anti-tumor marker antibody and its tumor antigen. All four antibody/antigen systems displayed the lowest SNR on APDMES surface and the highest one on chitosan surface, Jeffamine surface showing an intermediate behaviour. However, the most significant variations were obtained for the detection of DEFA6 with up to 7 times SNR on chitosan surface than on Jeffamine or APDMES surfaces (Figure 6D). For the other tumor markers, a maximum of 5 times SNR was obtained on chitosan surface compared to APDMES surface. These results confirmed that the binding capacity of chitosan surface for the immobilisation of antibodies is higher than that of Jeffamine and APDMES surfaces (Figure 4). Moreover, chitosan surface allowed maintaining the biological activity of the immobilized antitumor marker antibodies in order to efficiently detect tumor markers. 


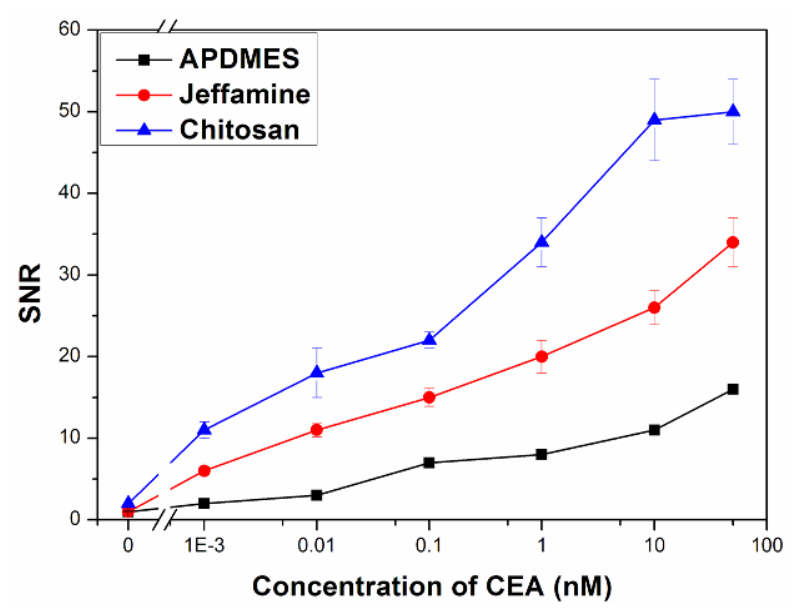

A

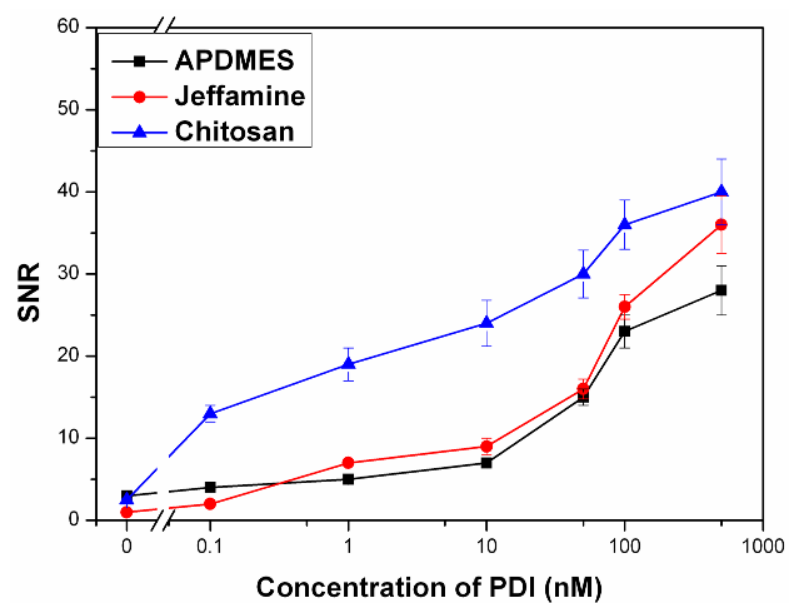

$\mathrm{C}$

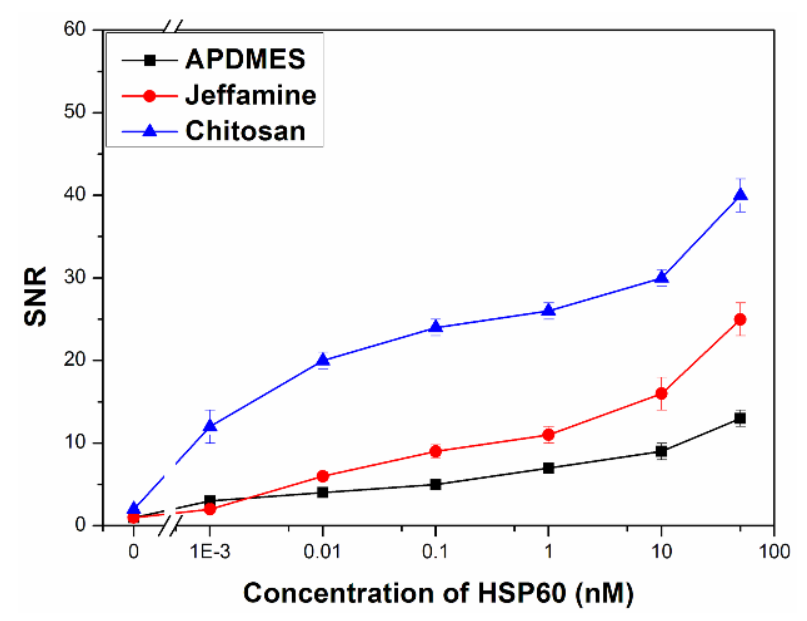

B

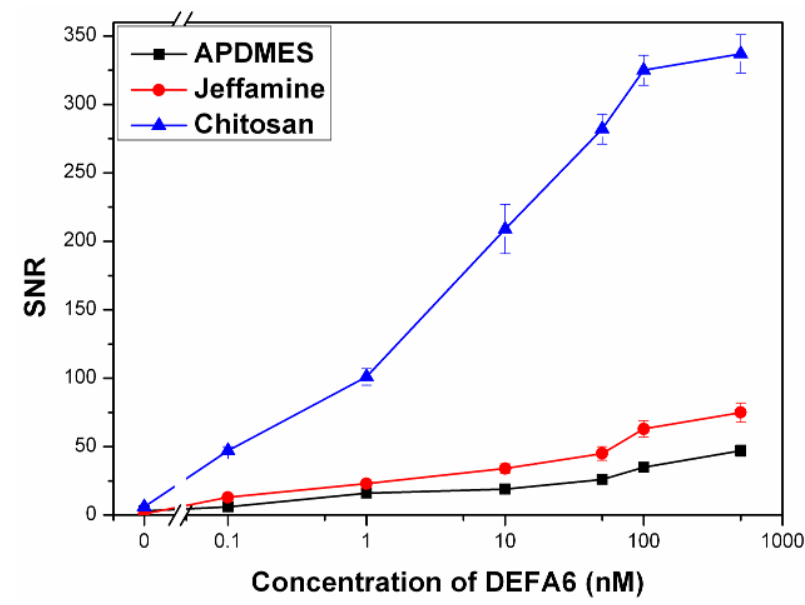

$\mathrm{D}$

Figure 6. Detection of tumor markers in multiplex immunoassays on aminated surfaces. (a) CEA, (b) HSP60, (c) PDI and (d) DEFA6; capture anti-tumor marker antibody concentration was $10 \mu \mathrm{M}$ spotted in sodium carbonate buffer $\mathrm{pH}=9.6$.

Additionally, SNR curves obtained for CEA and DEFA6 on chitosan surface showed saturation plateau from $10 \mathrm{nM}$ and $100 \mathrm{nM}$ of tumor marker, respectively. This result suggested that maximum binding efficiency of biologically active immobilized antibodies was reached. For HSP60 and PDI, the saturation plateau was not reached in the tested range indicating that the detection of these two tumor markers was less efficient than the detection of CEA and DEFA6. 
On chitosan surface, the limit of detection for each tumor marker can reach their lowest tested concentration (CEA and Hsp60 1 pM, PDI and DEFA6 100 pM). Recently we reported that DEFA6 has the best analytical performance (a lowest limit of detection at $10 \mathrm{pM}$ and a broad dynamic range of $4.7 \log )$ on chitosan surface under the protein spotted in $20 \%(\mathrm{v} / \mathrm{v})$ glycerol/PBS (pH 7.4) ${ }^{10}$. In this paper, the signal could be detected even in the case of CEA and Hsp60 at 1 pM or below under optimal condition on chitosan surface.

Although APDMES surface displayed 2 times more amine density than Jeffamine and chitosan surfaces, it showed the lowest antibody immobilization efficiency and maintenance of biological activity. This was attributed to its low surface energy leading to poor wettability properties and to the shortness of the amino chains reducing binding surface capacity. On the contrary, chitosan surface was demonstrated to be the most hydrophilic surface leading to more efficient immobilization of antibodies and better biological activity. According to our results, surface energy and chain length were the leading parameters for protein immobilization. However, it may well be that the amine density of chitosan surface was underestimated due to diffusion limitation (steric hindrance). Other researchers also indicated ${ }^{6,47}$ that the most hydrophilic and biocompatible surfaces were favourable for the immobilization of proteins and limiting nonspecific adsorption. Moreover, the high antibody immobilization efficiency of chitosan surface could be attributed to its long amino chains increasing specific surface. Finally, chitosan is a hydrosoluble biopolymer suitable to preserve the biological activity of adsorbed proteins. 


\section{CONCLUSION}

We designed and developed three different aminated surfaces, APDMES, Jeffamine and chitosan, on 3D microstructured glass slide to implement antibody microarray for the detection of tumor markers involved in colorectal cancer. Influences of amino chain length and physicochemical characteristics (surface energy, amine density) on antibody immobilization and on the ability to maintain their biological activity were studied. The efficiency of antibody immobilization was evaluated using fluorescent-labeled antibody allowing to compare the relative surface density obtained with the three aminated surfaces. Similarly, the relative biological activity of immobilized antibody on each surface was addressed using a sandwich assay with secondary fluorescent-labeled detection antibody. For all tested antibody/antigen systems, significantly enhanced signal-to-noise ratio was obtained on chitosan surface. This surface displayed the highest surface energy and chain length. Furthermore, sodium carbonate buffer ( $\mathrm{pH}$ 9.6) was found to be the optimal spotting buffer on the three amino-functionalized surfaces. Thus to improve the analytical performance of protein microarray it is required to optimize surface chemistry and immobilization conditions. In conclusion, antibody microarrays based on physical adsorption of proteins on aminated surfaces were successfully developed to supply simple and effective tools for the detection of tumor markers. Future work will focus on the detection of tumor markers from colorectal cancer sera using our optimized antibody microarray. 


\section{AUTHOR INFORMATION}

\section{Corresponding Author}

*E-mail address: emmanuelle.laurenceau@ec-lyon.fr. Tel.: +33 (0)4 7218 62 40; fax: +33 (0)4 72186250.

The first author (Z.G. Yang) has moved to: Department of Chemistry, University of Cambridge, Lensfield Road, Cambridge CB2 1EW, United Kingdom.

\section{ACKNOWLEDGMENTS}

China Scholarship Council is grateful to offer PhD fellowship to Z.G Yang. CNANO RhôneAlpes and BQR Ecole Centrale de Lyon are acknowledged for financial support and thanks NanoLyon for its technical support. 


\section{REFERENCES}

1 Luo, W.; Pla-Roca, M.; Juncker, D. Taguchi Design-Based Optimization of Sandwich Immunoassay Microarrays for Detecting Breast Cancer Biomarkers. Anal. Chem. 2011, 83, 57675774 .

2 Wu, J.; Fu, Z.; Yan, F.; Ju, H. Biomedical and clinical applications of immunoassays and immunosensors for tumor markers. Trac-Trend. Anal. Chem. 2007, 26, 679-688.

3 Sun, Z.; Fu, X.; Zhang, L.; Yang, X.; Liu, F.; Hu, G. A protein chip system for parallel analysis of multi-tumor markers and its application in cancer detection. Anticancer Res. 2004, 24, 1159-65.

4 Angenendt, P.; Glokler, J.; Murphy, D.; Lehrach, H.; Cahill, D. J. Toward optimized antibody microarrays: a comparison of current microarray support materials. Anal. Biochem. 2002, 309, 253-260.

5 Bi, Q.; Cen, X.; Wang, W.; Zhao, X.; Wang, X.; Shen, T.; Zhu, S. A protein microarray prepared with phage-displayed antibody clones. Biosens. Bioelectron. 2007, 22, 3278-3282.

6 Kusnezow, W.; Jacob, A.; Walijew, A.; Diehl, F.; Hoheisel, J. D. Antibody microarrays: an evaluation of production parameters. Proteomics 2003, 3, 254-64.

7 Niemeyer, C. M. Semisynthetic DNA-Protein Conjugates for Biosensing and Nanofabrication. Angew. Chem. Int. Ed. 2010, 49, 2-19.

8 Seurynck-Servoss, S. L.; White, A. M.; Baird, C. L.; Rodland, K. D.; Zangar, R. C. Evaluation of surface chemistries for antibody microarrays. Anal. Biochem. 2007, 371, 105-115.

9 El Khoury, G.; Laurenceau, E.; Chevolot, Y.; Merieux, Y.; Desbos, A.; Fabien, N.; Rigal, D.; Souteyrand, E.; Cloarec, J. P. Development of miniaturized immunoassay: Influence of surface chemistry and comparison with enzyme-linked immunosorbent assay and Western blot. Anal. Biochem. 2010, 400, 10-18.

10 Yang, Z.; Chevolot, Y.; Ataman-Önal, Y.; Choquet-Kastylevsky, G.; Souteyrand, E.; Laurenceau, E. Cancer biomarkers detection using 3D microstructured protein chip: Implementation of customized multiplex immunoassay. Sensor. Actuat. B-Chem. 2012, 175, $22-$ 28.

11 Zhu, H.; Snyder, M. Protein chip technology. Curr. Opin. Chem. Biol. 2003, 7, 55-63.

12 Jonkheijm, P.; Weinrich, D.; Schroder, H.; Niemeyer, C. M.; Waldmann, H. Chemical Strategies for Generating Protein Biochips. Angew. Chem. Int. Ed. 2008, 47, 9618-9647.

13 Rusmini, F.; Zhong, Z. Y.; Feijen, J. Protein immobilization strategies for protein biochips. Biomacromolecules 2007, 8, 1775-1789.

14 Zhou, X. C.; Zhou, J. Z. Protein microarrays on hybrid polymeric thin films prepared by self-assembly of polyelectrolytes for multiple-protein immunoassays. Proteomics 2006, 6, 14151426.

15 Kim, J. K.; Shin, D. S.; Chung, W. J.; Jang, K. H.; Lee, K. N.; Kim, Y. K.; Lee, Y. S. Effects of polymer grafting on a glass surface for protein chip applications. Colloid. Surface. $B$ 2004, 33, 67-75.

16 Prabhulkar, S.; Alwarappan, S.; Liu, G.; Li, C.-Z. Amperometric micro-immunosensor for the detection of tumor biomarker. Biosens. Bioelectron. 2009, 24, 3524-3530.

17 Yang, Z.; Chevolot, Y.; Géhin, T.; Solassol, J.; Mange, A.; Souteyrand, E.; Laurenceau, E. Improvement of protein immobilization for the elaboration of tumor-associated antigen microarrays: Application to the sensitive and specific detection of tumor markers from breast cancer sera. Biosens. Bioelectron. 2013, 40, 385-392. 
18 Laurenceau, E.; Yang, Z. G.; Chevolot, Y.; Attaman, Y.; Choquet-Kastylevsky, G.; Souteyrand, E. Tumor antigens titration on novel miniaturized immunoassay: 3D-Protein chip performance evaluation. Bull. Cancer 2011, 98, S70-S70.

19 Hamelin, C.; Cornut, E.; Poirier, F.; Pons, S.; Beaulieu, C.; Charrier, J.-P.; Haidous, H.; Cotte, E.; Lambert, C.; Piard, F.; Ataman-Onal, Y.; Choquet-Kastylevsky, G. Identification and verification of heat shock protein 60 as a potential serum marker for colorectal cancer. Febs. J. 2011, 278, 4845-4859.

20 Ataman-Onal, Y.; Beaulieu, C.; Busseret, S.; Charrier, J. P.; Choquet-Kastylevsky, G.; Rolland, D. Method for assaying Prodefensin-A6 for the in vitro diagnosis of colorectal cancer. WO 2010/112777, 2012.

21 Ataman-Onal, Y.; Beaulieu, C.; Busseret, S.; Charrier, J. P.; Choquet-Kastylevsky, G.; Rolland, D. Protein Disulfide Isomerase assay method for the in vitro diagnosis of colorectal cancer. WO 2010/004214, 2011.

22 Mazurczyk, R.; El Khoury, G.; Dugas, V.; Hannes, B.; Laurenceau, E.; Cabrera, M.; Krawczyk, S.; Souteyrand, E.; Cloarec, J. P.; Chevolot, Y. Low-cost, fast prototyping method of fabrication of the microreactor devices in soda-lime glass. Sensor. Actuat. B-Chem. 2008, 128, 552-559.

23 Vieillard, J.; Mazurczyk, R.; Morin, C.; Hannes, B.; Chevolot, Y.; DesbèneP-L.; Krawczyk, S. Application of microfluidic chip with integrated optics for electrophoretic separations of proteins. J. Chromatogr. B 2007, 845, 218-225.

24 Zhang, J.; Pourceau, G.; Meyer, A.; Vidal, S.; Praly, J. P.; Souteyrand, E.; Vasseur, J. J.; Morvan, F.; Chevolot, Y. Specific recognition of lectins by oligonucleotide glycoconjugates and sorting on a DNA microarray. Chem. Comm. 2009, 6795-6797.

25 Chevolot, Y.; Zhang, J.; Meyer, A.; Goudot, A.; Rouanet, S.; Vidal, S.; Pourceau, G.; Cloarec, J.-P.; Praly, J.-P.; Souteyrand, E.; Vasseur, J.-J.; Morvan, F. Multiplexed binding determination of seven glycoconjugates for Pseudomonas aeruginosa Lectin I (PA-IL) using a DNA-based carbohydrate microarray. Chem. Comm. 2011, 47, 8826-8828.

26 Dugas, V.; Depret, G.; Chevalier, B.; Nesme, X.; Souteyrand, E. Immobilization of single-stranded DNA fragments to solid surfaces and their repeatable specific hybridization: covalent binding or adsorption? Sensor. Actuat. B-Chem. 2004, 101, 112-121.

27 Zhang, J.; Pourceau, G.; Meyer, A.; Vidal, S.; Praly, J.-P.; Souteyrand, E.; Vasseur, J.-J.; Morvan, F.; Chevolot, Y. DNA-directed immobilisation of glycomimetics for glycoarrays application: Comparison with covalent immobilisation, and development of an on-chip IC50 measurement assay. Biosens. Bioelectron. 2009, 24, 2515-2521.

28 Chamieh, J.; Faye, C.; Dugas, V.; Moreau, T.; Vandenabeele-Trambouze, O.; Demesmay, C. Preparation and full characterization of a micro-immunoaffinity monolithic column and its inline coupling with capillary zone electrophoresis with Ochratoxin A as model solute. $J$. Chromatogr. A 2012, 1232, 93-100.

29 Coussot, G.; Faye, C.; Ibrahim, A.; Ramonda, M.; Dobrijevic, M.; Le Postollec, A.; Granier, F.; Vandenabeele-Trambouze, O. Aminated dendritic surfaces characterization: a rapid and versatile colorimetric assay for estimating the amine density and coating stability. Anal. Bioanal. Chem. 2011, 399, 2295-2302.

30 Coussot, G.; Perrin, C.; Moreau, T.; Dobrijevic, M.; Le Postollec, A.; VandenabeeleTrambouze, O. A rapid and reversible colorimetric assay for the characterization of aminated solid surfaces. Anal. Bioanal. Chem. 2011, 399, 1061-1069. 
31 Alexander, M. R.; Short, R. D.; Jones, F. R.; Michaeli, W.; Blomfield, C. J. A study of HMDSO/O-2 plasma deposits using a high-sensitivity and -energy resolution XPS instrument: curve fitting of the Si 2p core level. Appl. Surf. Sci. 1999, 137, 179-183.

32 Phaner-Goutorbe, M.; Dugas, V.; Chevolot, Y.; Souteyrand, E. Silanization of silica and glass slides for DNA microarrays by impregnation and gas phase protocols: A comparative study. Mater. Sci. Eng., C 2011, 31, 384-390.

33 Coussot, G.; Nicol, E.; Commeyras, A.; Desvignes, I.; Pascal, R.; VandenabeeleTrambouze, O. Colorimetric quantification of amino groups in linear and dendritic structures. Polym. Int. 2009, 58, 511-518.

34 Oh, S. J.; Cho, S. J.; Kim, C. O.; Park, J. W. Characteristics of DNA microarrays fabricated on various aminosilane layers. Langmuir 2002, 18, 1764-1769.

35 Zhang, F.; Sautter, K.; Larsen, A. M.; Findley, D. A.; Davis, R. C.; Samha, H.; Linford, M. R. Chemical Vapor Deposition of Three Aminosilancs on Silicon Dioxide: Surface Characterization, Stability, Effects of Silane Concentration, and Cyanine Dye Adsorption. Langmuir 2010, 26, 14648-14654.

36 Dugas, V.; Chevalier, Y. Surface hydroxylation and silane grafting on fumed and thermal silica. J. Colloid. Interf. Sci. 2003, 264, 354-361.

37 Noel, S.; Liberelle, B.; Robitaille, L.; De Crescenzo, G. Quantification of Primary Amine Groups Available for Subsequent Biofunctionalization of Polymer Surfaces. Bioconjug. Chem. 2011, 22, 1690-1699.

38 White, L. D.; Tripp, C. P. Reaction of (3-Aminopropyl)dimethylethoxysilane with Amine Catalysts on Silica Surfaces. J. Colloid. Interface. Sci. 2000, 232, 400-407.

39 Shearer, J. C.; Fisher, M. J.; Hoogeland, D.; Fisher, E. R. Composite SiO2/TiO2 and amine polymer/TiO2 nanoparticles produced using plasma-enhanced chemical vapor deposition. Appl. Surf. Sci. 2010, 256, 2081-2091.

40 Shircliff, R. A.; Martin, I. T.; Pankow, J. W.; Fennell, J.; Stradins, P.; Ghirardi, M. L.; Cowley, S. W.; Branz, H. M. High-Resolution X-ray Photoelectron Spectroscopy of Mixed Silane Monolayers for DNA Attachment. ACS Appl. Mater. Interfaces 2011, 3, 3285-3292.

41 Dugas, V.; Chevalier, Y. Chemical Reactions in Dense Monolayers: In Situ Thermal Cleavage of Grafted Esters for Preparation of Solid Surfaces Functionalized with Carboxylic Acids. Langmuir 2011, 27, 14188-14200.

42 Kallury, K. M. R.; Macdonald, P. M.; Thompson, M. Effect of Surface-Water and Base Catalysis on the Silanization of Silica by (Aminopropyl)Alkoxysilanes Studied by X-Ray Photoelectron-Spectroscopy and C-13 Cross-Polarization Magic-Angle-Spinning NuclearMagnetic-Resonance. Langmuir 1994, 10, 492-499.

43 McLean, K. M.; Johnson, G.; Chatelier, R. C.; Beumer, G. J.; Steele, J. G.; Griesser, H. J. Method of immobilization of carboxymethyl-dextran affects resistance to tissue and cell colonization. Colloid. Surface. B 2000, 18, 221-234.

44 Drogoz, A.; Munier, S.; Verrier, B.; David, L.; Dornard, A.; Delair, T. Towards biocompatible vaccine delivery systems: Interactions of colloidal PECs based on polysaccharides with HIV-1 p24 antigen. Biomacromolecules 2008, 9, 583-591.

45 Schatz, C.; Pichot, C.; Delair, T.; Viton, C.; Domard, A. Static light scattering studies on chitosan solutions: From macromolecular chains to colloidal dispersions. Langmuir 2003, 19, 9896-9903.

46 Wu, Y.-C.; Lee, T.-M.; Lin, J.-C.; Shaw, S.-Y.; Yang, C.-Y. Argon-Plasma-Treated Chitosan: Surface Characterization and Initial Attachment of Osteoblasts. J. Biomat. Sci-Polym.

E. 2010, 21, 563-579. 
47 Ruckenstein, E.; Li, Z. F. Surface modification and functionalization through the selfassembled monolayer and graft polymerization. Adv. Colloid. Interfac. 2005, 113, 43-63.

\section{TOC Graphic}
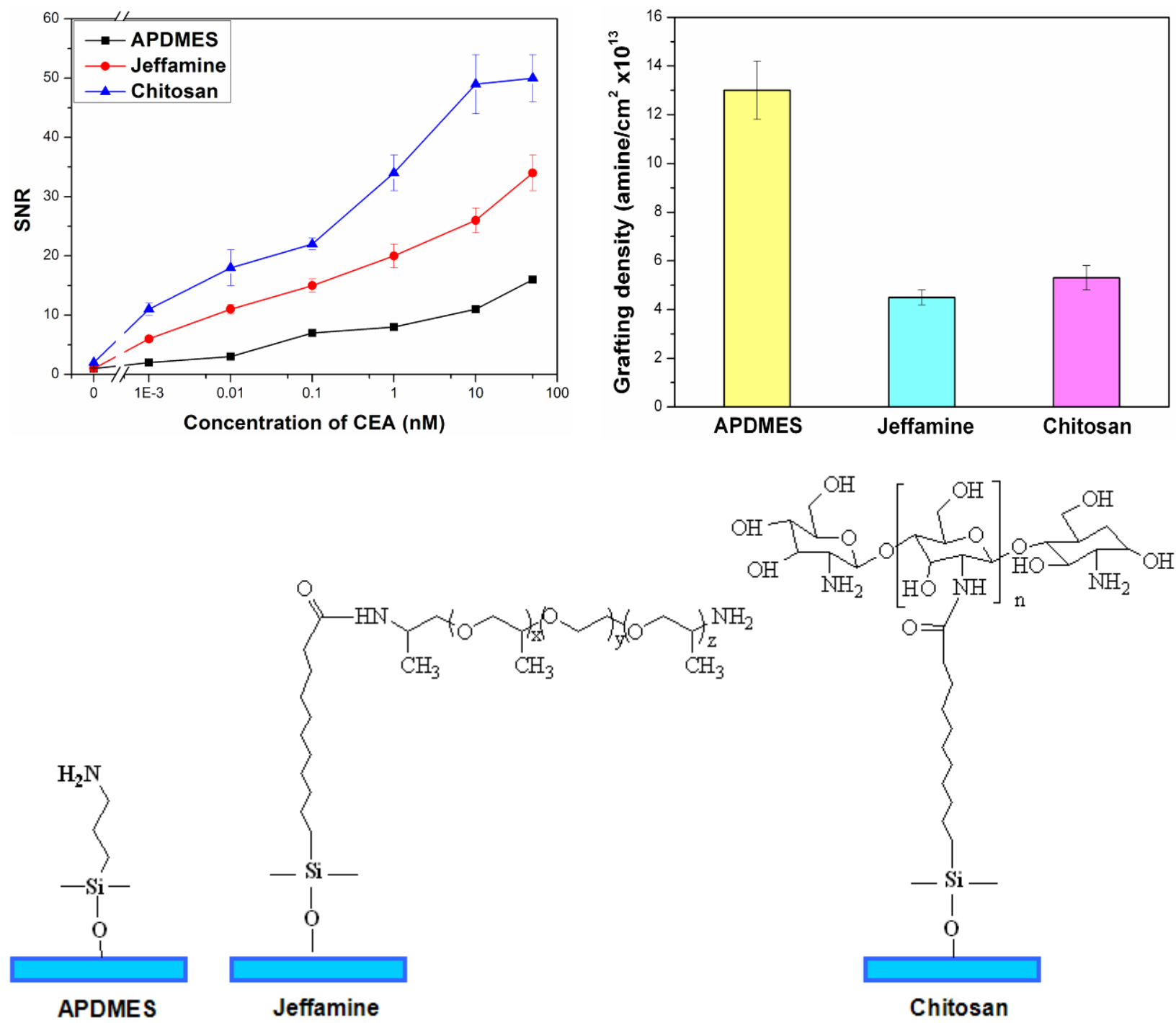